\title{
PSO_PI Controller of Robotic Grinding Force Servo System
}

\author{
Adnan Jabbar Attiya ${ }^{\star 1}$, Yang Wenyu ${ }^{2}$, Salam Waley Shneen ${ }^{3}$ \\ ${ }^{1,2}$ School of Mechanical Science and Engineering, Huazhong University of Science and Technology, \\ (HUST) Luoyu Road 1037, Wuhan 430074, China \\ ${ }^{1}$ Alkwarizmi Engineering College / Baghdad University, Baghdad, Iraq \\ ${ }^{3}$ Huazhong University of Science and Technology (HUST) / University of Technology, \\ Baghdad, Iraq \\ ${ }^{*}$ Corresponding author, e-mail address: rainman3009@yahoo.com", \\ mewyang@mail.hust.edu.cn ${ }^{2}$, Salam_waley73@yahoo.com ${ }^{3}$
}

\begin{abstract}
When an industrial robot is used to grind a curved surface, as marine propeller surface, contact force and feed movement must controlled together at the similar time in order that the grinding tool would machine the work-piece, with required force, at the right position in right posture. A passive wrist system is advanced. In this paper, to conform the shape of the machining propeller by altering its posture along with the surface. Grinding force is controlled under a simple new PSO-PI controller at a steady value in the normal direction of the mentioned machining point by multi-point machining, while the grinding tool moving along the curved surface of the propeller. It means that the model of the passive wrist system and the surroundings could be used in force controlling when robots grind marine propeller surface by a grinding tool with multi-point machining. PSO_PI controller policy is being assembled and compared with a $P I$ controller to obtain a controller that provides grinding with higher quality. The compared controllers have been optimized together with the parameters of the Two-Phase Hybrid Stepping Motor. The particle swarm optimization (PSO) method was selected from several methods to optimize of Proportional-Integral controller parameters in order to give better performance with improved step response for robotic grinding force servo system and overshoot are reduced. This control method was simulated using MATLAB/SIMULINK.
\end{abstract}

Keywords: PI control, particle swarm optimization (PSO), PSO- PI control, force control, grinding robot

Copyright $@ 2015$ Institute of Advanced Engineering and Science. All rights reserved.

\section{Introduction}

Grinding is a chip-removing process fundamental used to remove burrs and metal from machined parts in order to accomplish the desired surface finish. In many cases, manual grinding means monotonous and hard work in a noisy environment. The workers required to use protective equipment. So this leads to automation of the grinding process. Robotic grinding, in early industrial applications, was resolved using a grinding machine attached to the end effector of robot through a damper and spring arrangement. The requested contact force between the grinding tool and the workpiece was achieved by programming the robot's position to be slightly under the workpiece surface. It was difficult to control the depth of cut and accomplish optimal grinding conditions because of alterations in the grinding tool and workpiece geometry wear would cause alterations in the contact forces. Also, the workpiece geometry was required to be measured regularly, which was quite boring. Therefore, there was a require for an intelligent robot control system and more flexible taking care of the requirements from the grinding process [1]. In the process of grinding and finishing, grinding force needs to be actively controlled both in direction and in value all the time along with feed movement controlling, thus the process requires to be controlled by the policy of compliant controlling.

When the force controlled robot is applied to grinding operation, the position control style is selected to control the grinding tool path in the feed direction exactly. In the press direction, which is perpendicular to the feed direction, the compliance control style or force control style is selected to get the appropriate contact force. It is essential to maintain a suitable amount of contact force in grinding operation, and as well to take into account the workpiece profile after grinding. There are two cases for the grinding operation [2]. The first is surface 
grinding or deburring the machined parts in which a grinding tool traces the workpiece profile. The second is bead grinding or deburring the forged or cast parts, in which the perfect profile must be accomplished after grinding. Either compliance control or force control can be chosen. The difference in grinding between using compliance control and force control is as is explained in the coming section.

In the force control style, the grinding tool follows the surface of workpiece by maintaining the contact force constant. So it is possible to follow an unknown curved surface. The grinding process can be finished easily without taking into account the position errors like for example in setting the workpiece, that is the problem when using a position controlled robot. This style therefore is most successfully for grinding a surface usually made or in small deburring of machined parts. In the compliance control style, the requested profile of the workpiece surface after grinding process performs as the reference position, also the contact force is accomplished by contraction or expansion of virtual spring. So it is possible to produce a target profile after grinding. Then, it must be compensate the large error of workpiece position that can't be corrected by virtual spring. This style is appropriate for grinding to get a target profile as an example of large deburring of casting. Force control is used to preserve a constant force on the part during the marine propeller grinding process, as an example, in order to provide equally grinding on the whole surface. Passive compliance is an additional tool or a device attached to the robot end-effector to provide a flexibility for it and has a number of advantages including: Passive compliance is useful for the self-correction of positioning errors in assembly, normally reduce the high forces or moments produced in wedging or jamming, passive compliance protect the assembled surfaces from damage, such as a galling or scraping; it is useful also for adaptation to the impermanent state control and force control. In a robotic grinding procedure, it is essential to perform the workpiece given geometry, so it is commonly required that the robot performs a given path while preserving the contact between the grinding tool and the workpiece. Any divergences from the programmed path arise from an increase of the contact force or yet in the loss of contact. This contact force is demanded to be maintained within a given value to assure that the tool can perform the material removal [3]. From control is attained, the velocity or force may be not continuous and the control becomes uncertain. In this condition, a passive compliance which attached to the robot end-effector near the contact point will absorbed the kinetic energy and could avoid the possible high forces or moments, therefore, the lack of continuity is accommodated and preformance of the complete system is smoothed [4]. Also, when the robot is equipped with passive compliance, a high gain of the force control can be chosen. So, for the system that contains passive compliance, the permitted force control gain is higher than that without it, which is desirable for improving performance and sensitiveness of force control. This paper present a helix spring and passive wrist to be the passive compliance additional tools. The hybrid movement-force control policy is the best way for a compliant control system to deal with the coupling of the force control subsystem and the movement control subsystem. A passive wrist system is improved, in this paper, to conform the shape of the propeller machining surface, and the PSO_PI control strategy is used to deal with the robots' position changing. In this method, force control is fulfilled in the normal direction of the mentioned machining point by multi-point machining during a grinding wheel moving along the curved surface of the propeller.

The controller will be PSO-PI, the conventional proportional-integral (PI) controllers stay to be the most prevalently used in the industrial processes. In practice, most physical systems have essentially ungovernable characteristics such as non-linearities and high order, hence, good PI tuning methods are excessively eligible due to their common use. The type of achieving the parameters of $\mathrm{PI}$ controllers that satisfy the execution requirement has been referred in many studies. The PI controller gains can be selected by many techniques such as trial and error method, Ziegler-Nichols method numerical and the developmental techniquesbased searching. The numerical values of the $\mathrm{PI}$ controller gains rely on the ratings of the motor [5]. Generally, the primary objective is the good load disturbance rejection. In addition, the closed-loop system should be robust against model errors [6]. The famous method, ZieglerNichols method, supplies a systematic tuning method for the PI parameters which has good load disturbance reduction but, with a long settling time and large overshoot it shows disappointing performance. For improving systems performance, such as, overshoot, rise time, and integral of the absolute error, many studies are endeavoring to combine features on the basis of the experiences of specialists with regard to PI gain scheduling, and the utilize of fuzzy

TELKOMNIKA Vol. 15, No. 3, September $2015: 515-525$ 
logic appears to be especially suitable. Lately, PSO_PI controllers have been displayed and inspected, and their adequate performance in several plants have been exhibited. The PSO is utilized offline to determine the controller parameters ( $\mathrm{Kp}$ and $\mathrm{Ki})$ [7]. Particle swarm optimization (PSO) is a swarm intelligence technique developed by Kennedy and Eberhart [8]. It is an algorithm for swarm intelligence based on population-based adaptive optimization, swarm theory and stochastic based on the simulation of animal social behaviors like fish swarms and bird flocks. Compared with other methods such as genetic computation, machine learning, and neural network learning, it furnishes better performance in computing accuracy, computing speed, and memory size in spite of the fact that the original PSO is very simple with only a few parameters to modify. Each parameter in PSO extremely affects the performance of PSO. Although, it is yet to be found how to determine suitable values of parameters in PSO that can be considered as level optimization [9]. The PSO based process to find the global maximum value of objective function. the main objective functions to be Minimized the rise time, minimize the maximum overshoot, Minimize the steady state error, Minimize the settling time, and Minimize speed tracking error [10-12].

\section{Principle of Grinding Force Controlling}

Grinding force is determined as shown in Figure 1, into three component forces, Fn which is normal grinding force, Ft which is tangential grinding force and a component force which is acting along the longitudinal feed direction which is neglected, usually, because of its unimportance. The normal grinding force $\mathrm{Fn}$ has an affect on the workpiece roughness and the surface deformation, while the tangential grinding force $\mathrm{Ft}$ chiefly influences the consumption of power and providing the grinding wheel life [13].

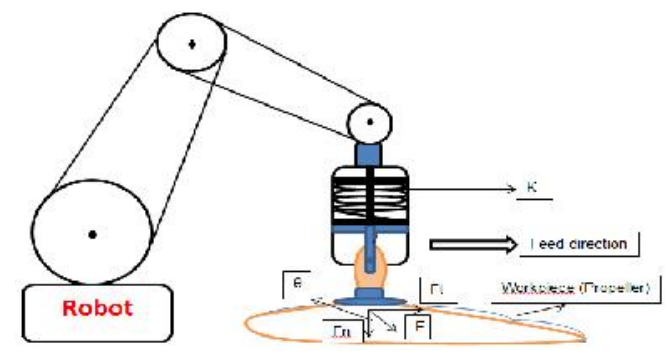

Figure 1. Main parameters used in grinding policies

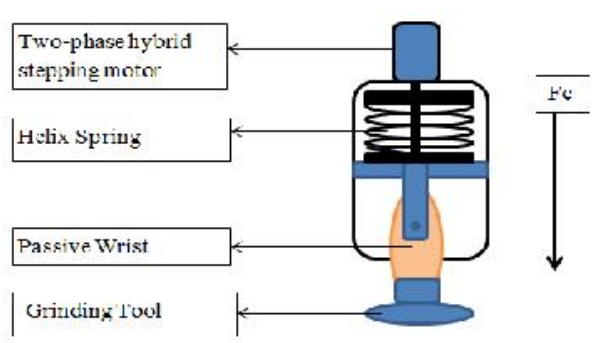

Figure 2. Model of the grinding force servo system

As shown in Figure 2, the compacting force Fc is regulated by two sections: Two-Phase Hybrid Stepping Motor and a Helix spring, passive wrist as a passive compliance.

Two-phase hybrid stepping motor is a brushless DC electric motor which divides a full rotation into a number of equal steps [14]. The position of motor can afterwards be ruled to move and hold without any feedback sensor at one of these steps, while the motor is cautiously sized to the application. The Two-phase hybrid stepping motor is famously used in controlling appliances with its dispositions of high precision, high torque output, low vibration and noisy, and low cost [15]. Thus, it is very significant that the control algorithm research applied in stepping motor. Stepper motors are fast and executable in many performance hardware. The utilize of stepper motors has increased few years later as a result of:

a) Its better reliability due to the mechanical brushes elimination,

b) Higher torque-to-inertia ratio due to a lighter rotor,

c) Its better heat dissipation due to that the windings are situated on the stator not on the rotor,

d) Inexpensive.

Originally, stepper motors were designed to be employed in open-loop. Their intrinsic stepping capability allows for perfect positioning without feedback, then closed-loop control of stepper motors has been employed to achieve more rapid response times and higher resolution 
capabilities. the stepper motor can also be operated at higher speeds, by taking into consideration nonlinear effects [16]. The stepper motor presses the helix spring when it works, and supplies the compressive force Fc for the force controlling system. By two perpendicular angle sensors, the two angles $\alpha$ and $\beta$ could be detected, and by a force sensor, the compressive force $\mathrm{Fc}$ is detected. The displacement of the linear stepper motor, founded on the data from sensors, is changed to compress the spiral spring to modify the grinding force Fn. The grinding force controlling diagram is shown in Figure 3, It is based according to the strategy of hybrid movement-force control, in which Fn is the surroundings target force, Fm symbolizes the modifying force to change the adapting of force controlling if needed.

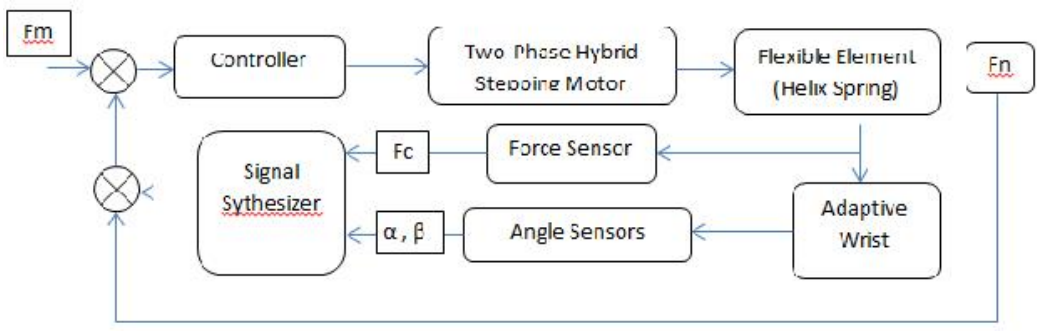

Figure 3. Block diagram of the force controlling system according to the strategy of hybrid movement-force control

The hardware system force controlling is designed, generally, by:

$$
\begin{aligned}
& I \_0=\left(I \_1+\mid \_2\right) / 2 \\
& \mathrm{Fn}=\mathrm{kf}\left(\mathrm{l} \_2 \text { I_1 }\right) / 2 \\
& \mathrm{Ft}=\mathrm{Fn} \\
& =\tan \theta
\end{aligned}
$$

Where: I 0 is the accurate displacement of the stepper motor when the grinding force at its desired value Fn, I_1 is the stepper motor greatest displacement, I_2 is the smallest displacement to compress the spiral spring, $\mathrm{Kf}$ is the elastic modulus of the spiral spring in Figure $1, \mathrm{Ft}$ is the tangential force and specific value per unit width, and is the grinding force ratio.

\section{The Model of the Two-phase Hybrid Stepping Motor}

The transfer function $\mathrm{G}(\mathrm{s})$ of the open-loop system of the two-phase Hybrid Stepping Motor is as follows [17]:

$$
G(s)=\frac{A(s)}{B(s)}
$$

Where:

$$
\begin{aligned}
\mathrm{A}(\mathrm{s}) & =(\mathrm{KPis}+\mathrm{KIi}) \mathrm{KH} \\
\mathrm{B}(\mathrm{s}) & =\mathrm{s}(\mathrm{THs}+1)(\mathrm{Ls}+\mathrm{R})+(\mathrm{KPis}+\mathrm{KIi}) \mathrm{KH} \\
& =\mathrm{LTHs}^{3}+(\mathrm{RTH}+\mathrm{L}) \mathrm{s}^{2}+\mathrm{Rs}+(\mathrm{KPis}+\mathrm{KIi}) \mathrm{KH}
\end{aligned}
$$


The subdivided driving is assumed for the Hybrid Stepping Motor in order to reach to the actual system performance parameter and to decrease the intricacy of the system transfer function. In simulation, the parameters of the two-phase Hybrid Stepping Motor selected are as follows:

Inertia Constant $\mathrm{J}=250 \mathrm{~kg} \mathrm{~m}$, Inductance $\mathrm{L}=0.33 \mathrm{H}$, Resistance $\mathrm{R}=8 \quad,, \beta=1$, Coefficient of Viscous Friction $\mathrm{B}=0 \mathrm{~N} \mathrm{~m}$ s/rad, $\mathrm{Kpv}=500, \mathrm{Klv}=0, \mathrm{KPi}=5, \mathrm{Kli}=500$, $\mathrm{ke}=0.25 \mathrm{~N} \mathrm{~m} / \mathrm{A}, \mathrm{N}=180, \mathrm{KH}=15$ and $\mathrm{TH}=0$. The Transfer function will be:

$$
G(S)=\frac{75 s+7500}{0.33 s^{2}+83 s+7500}
$$

\section{Conventional PI Strategy for Grinding Force Servo Unit}

The most conventional PI controller or linear PI controller is described as follows:

$$
Y(t)=e(t) K p+K i \int_{0}^{t} e(t) d t
$$

Where $\mathrm{KP}$ is the proportional constant gain and $\mathrm{KI}$ is the integral constant gain according to manual expertise. The signal $e(t)$ is the error signal between the reference and the process output $c(t)$ it is explained as: $e(t)=r(t)-c(t)$.

Table 1 shows the effect of Kp and Ki to the controlled system, and the Simulink figure of PI controller is shown in Figure 4.

Table 1. the effect of $\mathrm{Kp}$ and $\mathrm{Ki}$ to the controlled system

\begin{tabular}{lllll}
\hline Parameter & Rise time & Overshoot & Turning time & Error \\
\hline $\mathbf{K p}$ & decrease & increase & Small change & decrease \\
$\mathbf{K i}$ & decrease & increase & increase & eliminte \\
\hline
\end{tabular}
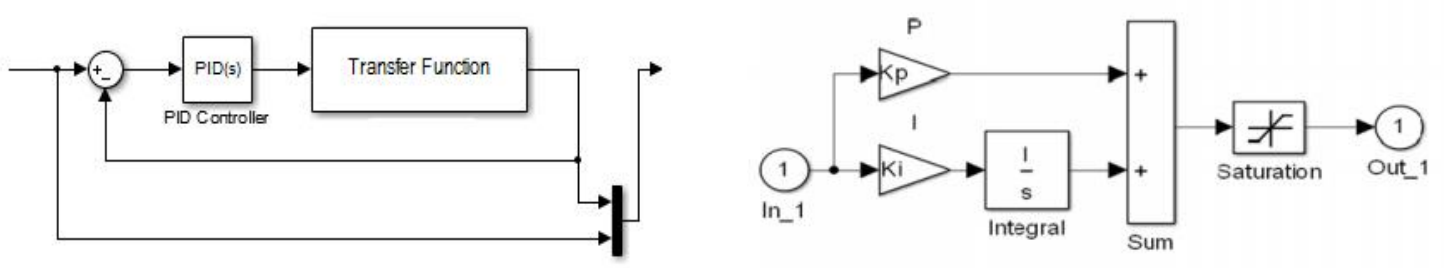

Figure 4. Simulink and Block diagram of PI controller

And the PI controller internal structure is explained in Figure 5, the input parameters for the $\mathrm{PI}$ controller are $\mathrm{Kp}, \mathrm{Ki}$, and the output for the controller is $\mathrm{u}$.

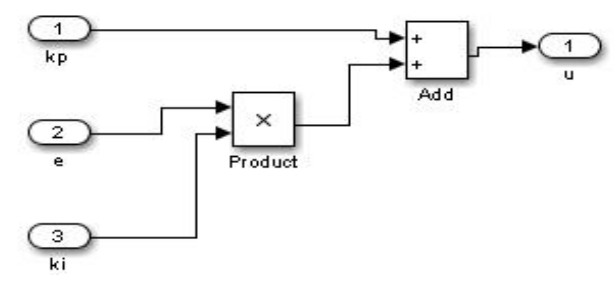

Figure 5. The structure for PI controller 


\section{Particle Swarm Optimization (PSO) Strategy for Grinding Force Servo Unit}

PSO algorithm has been a favorable technique for the optimization problems due to the simple idea, quick assembly, and easy implementation [18] It provides a population based search process in which particles vary their state (position) with time and strive to develop themselves by emulating characteristics from their successful peers. In addition, each particle has a memory and thus it is able to remember the best position in the search space ever visited by it [19]. In a PSO system, particles fly approximately in a multidimensional search space with an adaptable velocity which modified dynamically according to its own and the other particles flying experience. During flight, each particle modifies its position according to its own experience giving the best previous position (the minimum fitness value) is called personal best ( $\mathrm{P}$ best) which is recorded and delineated as $\mathrm{Pl}=(\mathrm{pi} 1, \mathrm{pi} 2, \ldots, \mathrm{pid})$, while the index of the best particle among all the neighboring particles in the population is called the global best (G best), it is delineated by the symbol $g$ and it is the best solution in the whole group [20].

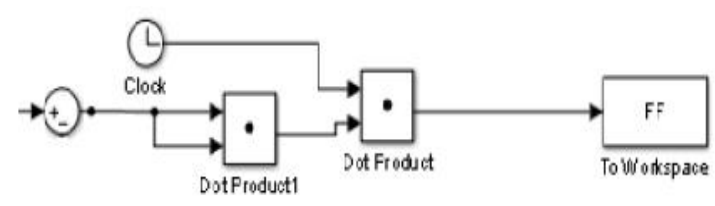

Figure 6. Particle swarm optimization (PSO) strategy

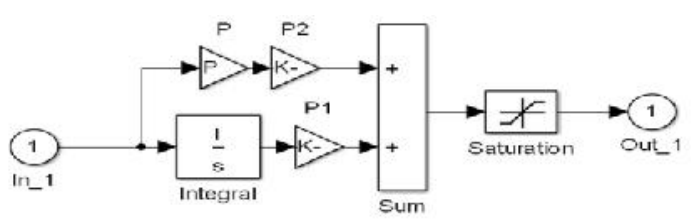

Figure 7. The structure of Particle swarm optimization (PSO) strategy

For a PI- controlled system, there are often four indices to characterize the system performance: ISE, IAE, ITAE and ITSE. In this paper we select ITSE which is defined as:

$$
\operatorname{ITSE}=\int_{0}^{\infty} \mathrm{te}^{2}(\mathrm{t}) \mathrm{dt}
$$

The modified PSO framework is described as follows:

1) Generate the initial velocity and position for each part randomly delineated one inputoutput system controller in particle according to its lower and upper values of each PI controller parameters in system to form parents [21].

2) For each part in each particle in the swarm, estimate $P$ best (the personal fitness).

3) To find the best PI controllers represented by the best parts in the swarm, evaluate $G$ best (the global best fitness) for all varied parts from all particles in the swarm.

4) Determine $G$ best of all particles in the population by adding all $G$ best for all parts from each particle in swarm.

5) Update each particle to form progeny.

6) Compare $P$ best (the personal fitness) of each part of progeny with their similar parts in parents and choose the best ones to form new offspring to the next generation.

7) Determine $G$ best (the global fitness) of the varied parts in the population as to the new offspring and adding to be the best ones for the next generation.

8) Stop if the stopping standard is satisfied otherwise, go to step 5. See Figure 8.

Each particle is treated as a point in a D-dimensional space. The ith particle is represented as $\mathrm{xi}=(\mathrm{xi} 1, \mathrm{xi} 2, \ldots, \mathrm{xid})$. The velocity of each agent which gradually gets close to Pbest and Gbest is represented as $v i=(v i 1, v i 2, \ldots, v i d)$, it can be adjusted by the following equation:

$$
v_{i d}^{n+1}=w \cdot v_{i d}^{n}+c 1 \cdot \operatorname{rand}() \cdot\left(p_{i d}^{n}-x_{i d}^{n}\right)+c 2 \cdot \operatorname{rand}() \cdot\left(p_{g d}^{n}-x_{i d}^{n}\right)
$$

Where $v_{i d}^{n}$ is current velocity, $v_{i d}^{n+1}$ is modified velocity, $n$ represents iteration, $w$ is an inertia weight, $\mathrm{p}_{\mathrm{id}}^{\mathrm{n}}=$ Pbest, $\mathrm{p}_{\mathrm{gd}}^{\mathrm{n}}=$ Gbest, $\mathrm{c} 1$ and $\mathrm{c} 2$ are two positive constants, rand ( ) is a random 
generated number with a range of $[0,1]$, and $\mathrm{x}_{\mathrm{id}}^{\mathrm{n}}$ is the current searching point. The searching point in the solution space or the current position can be adjusted by the following equation:

$$
\mathrm{x}_{\mathrm{id}}^{\mathrm{n}+1}=\mathrm{x}_{\mathrm{id}}^{\mathrm{n}}+\mathrm{v}_{\mathrm{id}}^{\mathrm{n}+1}
$$

As recommended in PSO, the constants are $\mathrm{c} 1=\mathrm{c} 2=0.8$, Equation (11) is used to calculate new velocity of the particle according to its previous velocity and its prevalent position distances of from its own best position (experience) and the group's best experience. Then the particle flies in the direction of a new position according to Equation (12). Inertia weight, $w$ in the Equation (11) is to make balance between the local search and global search capability. It can be a nonlinear function of time or positive constant or even positive linear [22]. In this paper we set $\mathrm{w}=0.3$.

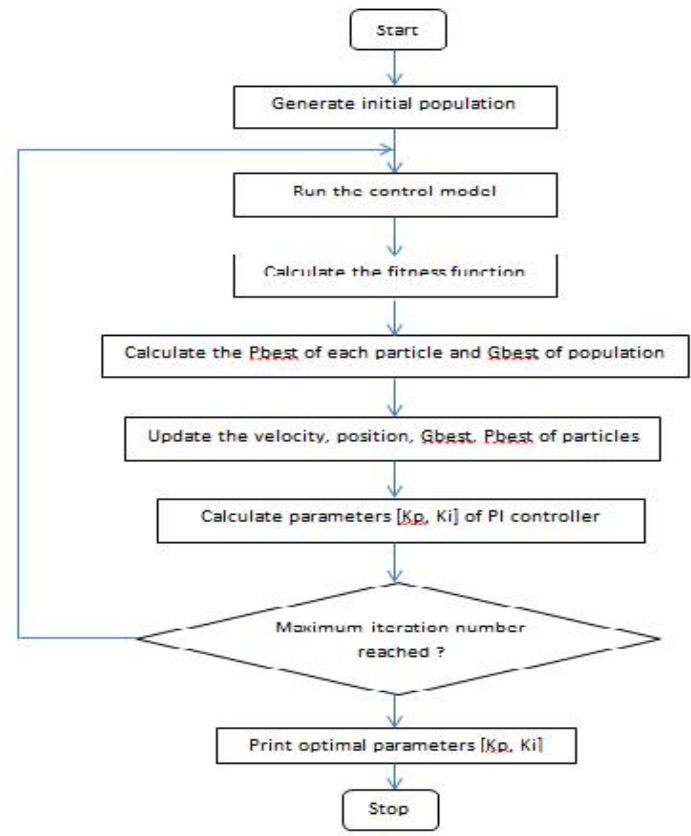

Figure 8. The flowchart of the PSO_PI control system

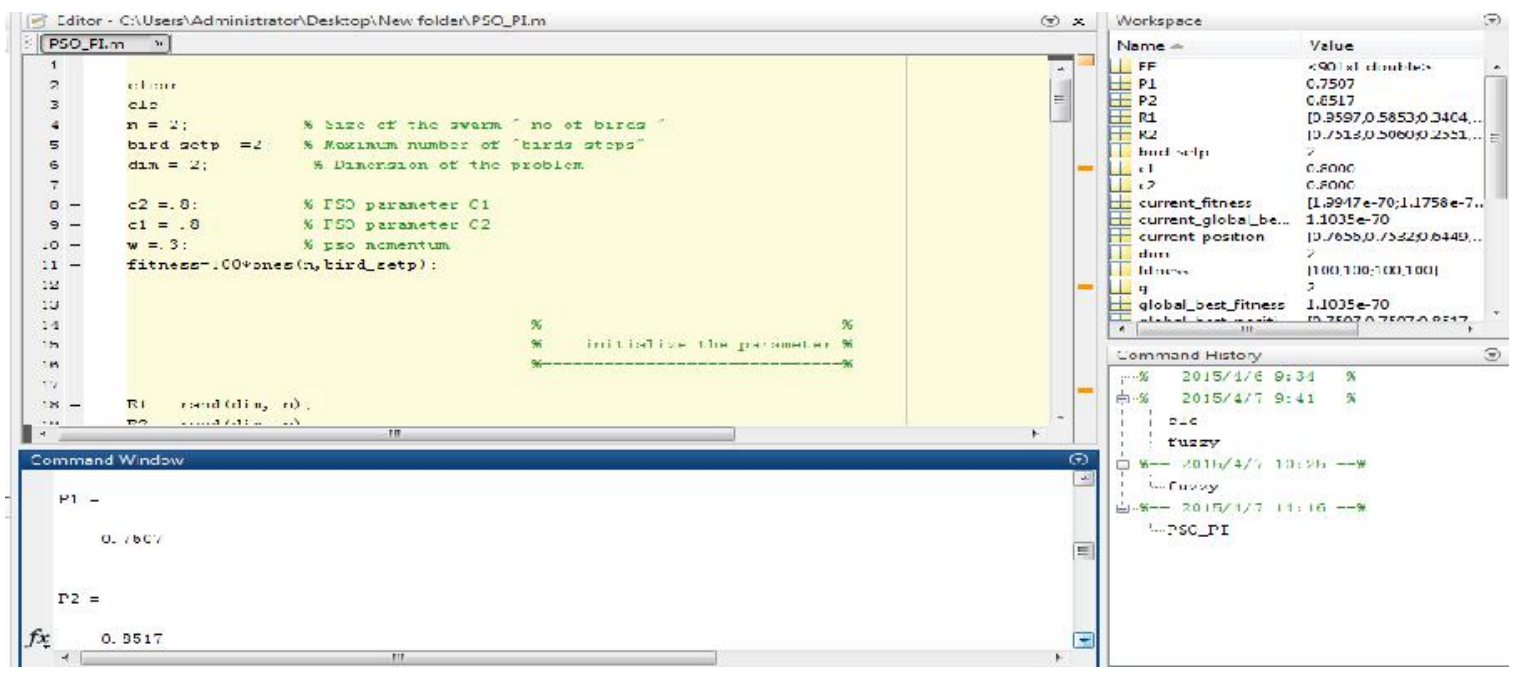

Figure 9. Steps of PSO-PI controller 


\section{Results and Discussion}

\subsection{Two-phase Hybrid Stepping Motor with PI Controller}

Figure 10 shows the Simulink figure of $\mathrm{PI}$ controller. When $\mathrm{Kp}=3, \mathrm{Ki}=40$, the simulation was performed in figure:

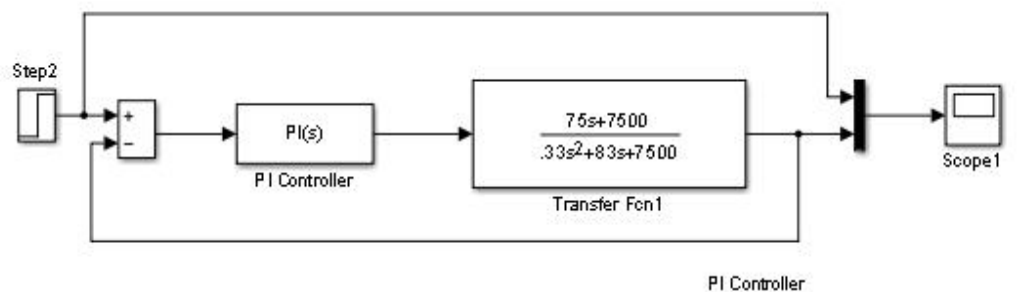

Figure 10. PI Controller

With the MATLAB SIMULINK, a famous simulation software, and for a conventional PI controlling system, step response is also shown in Figure 4 with $\mathrm{Kp}=3$ and $\mathrm{Ki}=40$

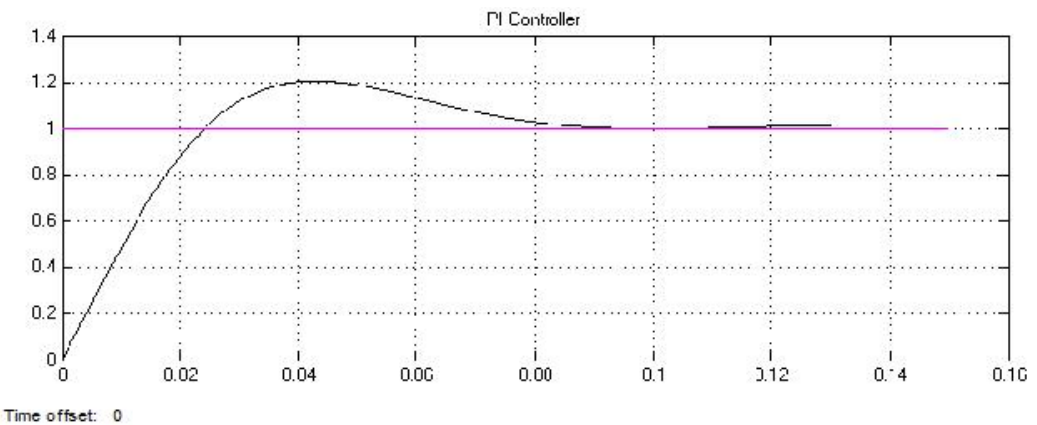

Figure 11. Step response of the system under PI controller

\subsection{Two-phase Hybrid Stepping Motor with PSO_PI Controller}

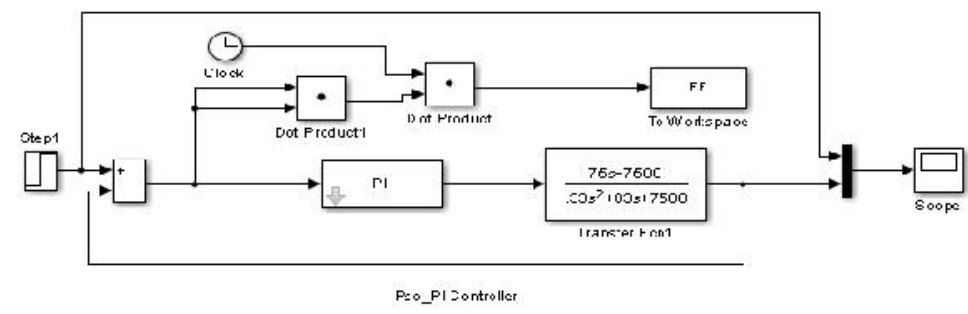

Figure 12. PSO_PI Controller

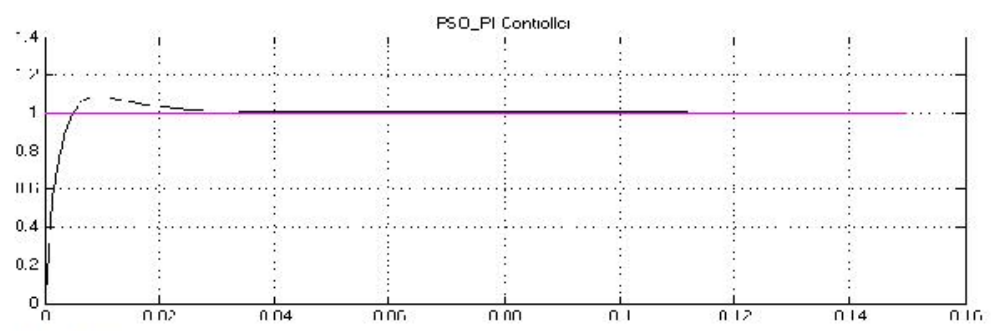

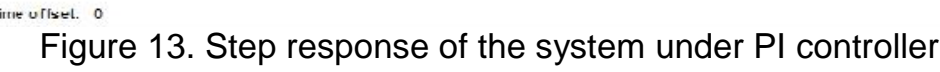


The hole system of the controller is shown in Figure 14.

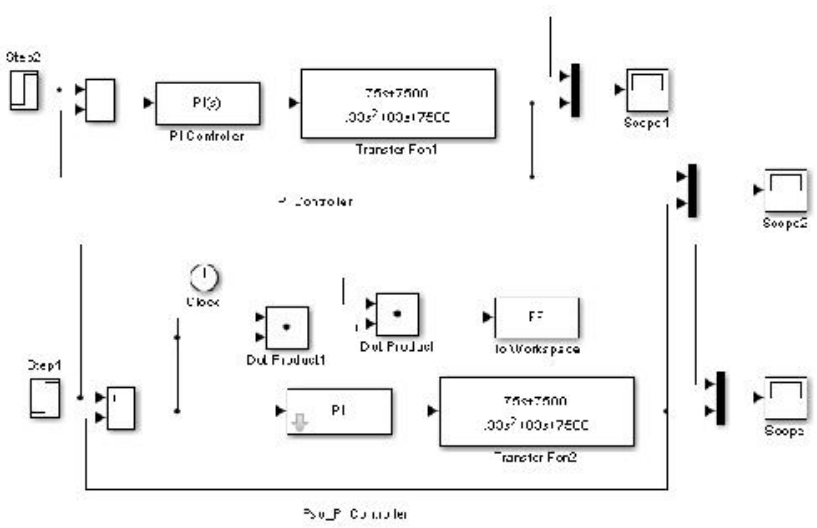

Figure 14. PSO_PI Controller of Robotic Grinding Force Servo System

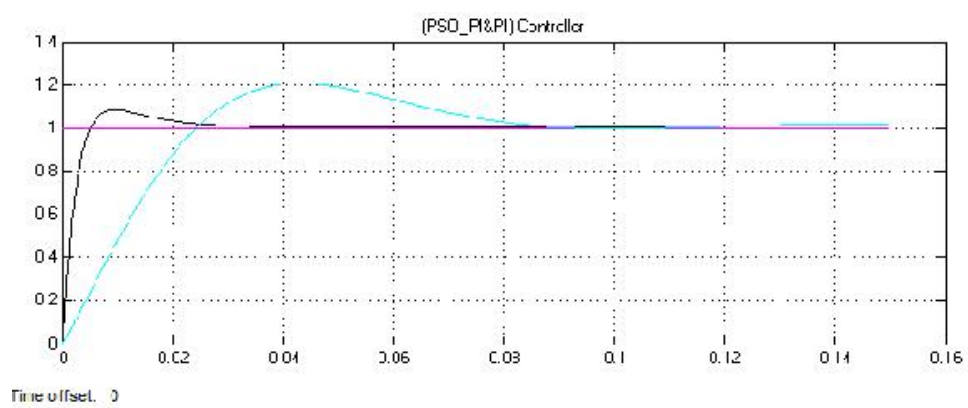

Figure 15. Step response of the system under PI \& PSO-PI controllers

Step response of the PSO- PI controlling system is completely different from that of the conventional PI controlling system. As shown in Figure 15 and Table 2, we note that when we use PI controller The Rise Time Value $=0.15$, the Overshoot value $=20$ and The Steady State Error $=0.035$. While when we use PSO-PI controller we note that the Rise Time value $=0.003$, the Overshoot value $=9$ and Steady State Error $=0.096$.

Remarkably, the PSO-PI controller has improved the force servo system by inferring the optimized Kp and Ki.

\begin{tabular}{cccc}
\multicolumn{3}{c}{ Table 2. Step response performance for PI\& PSO-PI controllers } \\
\hline Control Method & $\begin{array}{c}\text { Overshoot } \\
(\%)\end{array}$ & $\begin{array}{c}\text { Rise Time } \\
(\mathrm{s})\end{array}$ & $\begin{array}{c}\text { Steady State } \\
\text { Error }\end{array}$ \\
\hline PI & 20 & 0.015 & 0.096 \\
PSO-PI (ITAE) & 9 & 0.003 & 0.035 \\
\hline
\end{tabular}

\section{Conclusion}

When a grinding wheel grinds propellers as a free-form surfaces by a robot, the grinding force, at the mentioned machining point, must be controlled in the normal direction in order that both grinding force and feed movement could be controlled. Research works are taken for grinding force controlling in this paper.

(1) To make the grinding wheel conform the curved surface, passive wrist system is improved. The wrist could change its attitude in perpendicular two directions to conform the machining surface according to a helix spring compressive force that driven by a stepper motor. In this way, the grinding wheel could grind the free-form surfaces of marine propellers. 
(2) Whereas the controlling parameters would not be adapted with the attitude of the wrist altering and the controlling system is not capable of adapting one to the form of the machining surface, the grinding force could not be controlled at its aim value and the error is growing with the feed movement. It means that, the model of the surroundings and the passive wrist system could be used in force controlling when robots grind free-form surfaces of marine propellers with multi-point machining by a grinding wheel.

(3) From the results, the designed PI controllers using PSO based optimization have less Overshoot, less Rise time and less Steady State Error compared to that of the classical method (Z-N). The advantage of using this modern optimization approach is remarked as a complete solution to improve the PI controller performance to support good stability of the drive during parameter variations in the controllers of the robotic grinding force servo System.

\section{Acknowledgements}

This work was partially supported by the National Basic Research Program of China (2014CB046704).

\section{References}

[1] Trygve Thomessen, Terje K Lien, Per K Sannñs. Robot control system for grinding of large hydro power turbines. Industrial Robot: An International Journal. 2001; 28(4): 328-334.

[2] Kunio Kashiwagi, Kozo Ono, Eiki Izumi, Tohru Kurenuma, Razuyoshi Yamada. Force controlled robot for grinding. IEEE International Workshop on Intelligent Robots and Systems. 1001-1006.

[3] Paulo Abreu, Manuel Rodrigues Quintas. Pneumatic Driven Device for Integration into Robotic Finishing Applications. Springer-Verlag Berlin Heidelberg. 2013: 49-56.

[4] Xu Yangsheng. Control Software of Robot Compliant Wrist System. Technical Reports (CIS). Paper 564. 1990.

[5] Radha Thangaraj1, Thanga Raj Chelliah, Millie Pant, Ajith Abraham, Crina Grosan. Optimal gain tuning of PI speed controller in induction motor drives using particle swarm optimization. Logic Journal of IGPL Advance Access. 2010.

[6] Saeed Tavakoli, Amir Banookh. Robust PI Control Design Using Particle Swarm Optimization. Journal of Computer Science and Engineering. 2010; 1(1):s 36-41.

[7] Youcef Bekakra, Djilani Ben. Attous for DFIG based wind turbine with MPPT. Int J Syst Assur Eng Manag. 2014; 5(3): 219-229.

[8] J Kennedy, RC Eberhart. Particle swarm optimization. Proceedings IEEE International Conference on Neural Networks IV. 1995: 1942-1948.

[9] Juing-Shian Chiou, Shun-Hung Tsai, Ming-Tang Liu. A PSO-based adaptive fuzzy PID-controllers. Simulation Modelling Practice and Theory. 2012; 26: 49-59.

[10] Manoj Kushwah, Prof Ashis Patra. Tuning PID Controller for Speed Control of DC Motor Using Soft Computing Techniques-A Review. Advance in Electronic and Electric Engineering. 2014; 4(2): 141148.

[11] Wang Jingfang. Two regional power system PSO PID Control Research. TELKOMNIKA Indonesian Journal of Electrical Engineering. 2015; 13(1): 33-41.

[12] He Jie, Hui Guo. A modified particle swarm optimization algorithm. TELKOMNIKA Indonesian Journal of Electrical Engineering. 2013; 11(10): 6209-6215.

[13] ZC Li, B Lin, YS Xu, J Hu. Experimental studies on grinding forces and force ratio of the unsteadystate grinding technique. Journal of Materials Processing Technology. 2002; 129: 76-80.

[14] Nguyen TD, Tseng KJ, Zhang S, Nguyen HT. A Novel Axial Flux Permanent-Magnet Machine for Flywheel Energy Storage System Design and Analysis. IEEE Transactions on Industrial Electronics. 2011; 58(9): 3784-3794.

[15] Zhang Tuanshan, Zhang Na, Wu Yuting. Study of driving bipolar stepper motors based on enhanced STM32. Electronic Measurement Technology. 2010; 33(10): 16-18.

[16] Andrew J Blauch, Marc Bodson, John Chiasson. High-speed Parameter Estimation of Stepper. Motors IEEE Transactions on control systems technology. 1993; 1(4): 270-279.

[17] Xu Wenqiang, Yan Jianhong. Derivation of Transmission Function Model of Two-phase Hybrid Stepping Motor. Space Electronic Technology. 2011; (3): 50-53.

[18] Mohamed Sayed, Sawsan Morkos Gharghory, Hanan Kamal. Gain Tuning PI controllers for Boiler Turbine Unit using a New Hybrid Jump PSO. Journal of Electrical Systems and Information Technology. 2015: 1-13.

[19] Rabindra Kumar Sahu, Sidhartha Panda, GT Chandra Sekhar. A novel hybrid PSO-PS optimized fuzzy PI controller for AGC in multi area interconnected power systems. Electrical Power and Energy Systems. 2015; 64: 880-893. 
[20] Lalitha MP, Reddy VCV, Usha V. Optimal DG placement for minimum real power loss in radial distribution systems using PSO. J Theor Appl Inf Technol. 2010; 13(2): 107-116.

[21] Sawsan Gharghory, Hanan Kamal. Modified PSO for Optimal Tuning of Fuzzy PID Controller. IJCSI International Journal of Computer Science. 2013; 10(2): 462-471.

[22] Mahmud Iwan Solihin, Lee Fook Tack, Moey Leap Kean. Tuning of PID Controller Using Particle Swarm Optimization (PSO). Proceeding of the International Conference on Advanced Science, Engineering and Information Technology. 2011: 458-461. 